\title{
The Effect of Ozonizing Sulfuric Acid Electrolyte with or without Ultrasonic Field on Anodizing some Aluminum Alloys
}

\author{
V.I. Vigdorovich ${ }^{1,3^{*}}$, N.V. Kolenchin ${ }^{2}$ \\ ${ }^{1}$ Department of Descriptive Geometry and Computer Graphics, Tambov State Technical University, \\ 112, Michurinskaya St., Tambov, 392032, Russia \\ ${ }^{2}$ Department of Materials Science and Technology of Structural Materials, Tyumen Industrial University, \\ 38, Volodarskogo St., Tyumen, Russia \\ ${ }^{3}$ All-Russian Research Institute of Use of Machinery and Oil Products in Agriculture, \\ 28, Novorubezhny Per., Tambov, 392022, Russia \\ *Corresponding author. Tel: + 7 (9027) 2665 72; E-mail: vits21@mail.ru
}

\begin{abstract}
X-ray diffraction and X-ray spectroscopic methods were used to study the distribution of the elemental composition and structure of the oxide layer during anodizing D16 and AD31 alloys in the ozonized sulfuric acid electrolyte with and without ultrasonic field. The fraction of $\gamma-\mathrm{Al}_{2} \mathrm{O}_{3}$ crystalline phase in the oxide layer is estimated, the effect of ozonizing and ultrasonic field on the oxide wear, its microhardness and pore formation is considered. In the process of anodizing, in addition to crystalline $\gamma-\mathrm{Al}_{2} \mathrm{O}_{3}$, an amorphous phase is also formed on the surface of aluminum alloys. The contribution of the first one increases with the concentration of ozone in the air mixture. At the same time, the porosity level of the oxide increases. Moreover, the pores with increased effective diameter occur. An increase in the ozone content leads to an increase in the rate of oxide formation; the microhardness and wear resistance of the oxide also increase due to an increase in the crystallinity level.
\end{abstract}

\section{Keywords}

Aluminum alloys; anodizing; cavitation; oxide; ozonizing; ultrasound.

\section{Introduction}

At present, there is no industry in which aluminum, one of the most common materials in nature, would not be used. The explored reserves of aluminum raw materials on the Earth far exceed iron reserves and are practically inexhaustible [1]. Its uniqueness is determined by physical and chemical properties of the metal. Aluminum easily forms stable compounds with oxygen and many other substances. As a result of such chemical and physical effects, alloys and compounds that are fundamentally different in their properties can be obtained. Aluminum is lighter than iron almost threefold that makes it interesting for the construction industry; and in the aircraft industry, aluminum-based alloys are the main structural material.

Low strength properties of a pure metal are levelled by additives of manganese, zinc, magnesium, and copper. However, to use aluminum compounds in contact with abrasive medium or friction, alloying alone is not enough. At present, many methods have been developed for hardening the surface of aluminum alloys with a thickness of more than $30 \mu \mathrm{m}$ by means of an electrochemical process to form solid oxide $\mathrm{Al}_{2} \mathrm{O}_{3}$. Oxygen-containing aqueous solutions of electrolytes are used as a working medium. The ionization of oxygen is determined by the energy of an electron. Two variants of oxygen ions formation are given in $[2,3]$ :

- dissociative capture of an electron at an electron energy of $6.7 \mathrm{eV}$

$$
\mathrm{O}_{2}+e \rightarrow \mathrm{O}^{-}+\mathrm{O}
$$

- dissociation of a neutral molecule at an electron energy of $17 \mathrm{eV}$

$$
\mathrm{O}_{2}+e \rightarrow \mathrm{O}^{-}+\mathrm{O}^{+}+e
$$

The potential for the formation of a negative ion $\mathrm{O}^{-}$as a result of resonance capture of an electron corresponds to $4.5 \mathrm{eV}$ [4]

$$
\mathrm{O}_{2}+e \rightarrow \mathrm{O}_{2}^{-}=>\mathrm{O}_{2}^{-} \rightarrow \mathrm{O}+\mathrm{O}^{-} .
$$


The oxide formation scheme will depend on the ionization conditions of the oxygen donors and their density in the reaction zone.

Thus, the condition for oxide formation is the need to activate oxygen and oxygen-containing components in the inter-electrode gap. To ionize the inter-electrode space, two main methods are used:

- conducting the process at high current and voltage densities;

- the variability of the current-conducting medium.

Anodizing is known to be one of the common ways to grow a thick oxide film on aluminum. Coatings up to $200 \mu \mathrm{m}$ thick are formed in media that moderately dissolve the oxide and consist of two layers: a non-porous formation directly adjacent to the metal and an outer, porous one, representing oxide cells in the form of hexagonal prisms with a channel in the center. It has been shown theoretically [5] that the distance between pore centers can not exceed double thickness of a nonporous barrier layer. In acid electrolytes [6], the structure of the surface layer is formed with a cell size of 50 to $200 \mathrm{~nm}$, and a pore diameter in the range of 15 to $80 \mathrm{~nm}$. Experimentally there were established certain relationships between the thickness of the barrier layer, wall thickness and pore diameter, which are 0.85:1:1 [7]. Oxygencontaining anions of the electrolyte are also oxygen donors. However, the bulk of the anions of the electrolyte are embedded in the film, forming chemical bonds with it (they are built into the oxide structure) and can be removed only when the film is destroyed $[8,9]$. The anodic coatings are mainly X-ray amorphous. Their microhardness reaches $5 \mathrm{GPa}$. Crystallization of the oxide depends on the nature of the electrolyte and the temperature mode during the breakdown phenomena in the barrier layer.

A common feature of the developed methods of oxide forming on the surface of aluminum alloys is the fact that the energy potential for activation of the oxide formation participants is created in a closed loop "electrode-conductive medium". The degree of ionization of oxygen and its participation priority in the process is not fully studied.

The first part of the paper presents the results of the study on the process of oxide formation, when oxygen activation was carried out outside the "conductive medium-electrode" system with its metered transfer into inter-electrode space.

The second part is devoted to the study of one of the effective methods to affect the near-electrode zone, which is based on the processes of compression of gas microbubbles and their rupture on the surface of the anode. Ozone is known as an active and universal oxidizer, whose redox potential $2.07 \mathrm{~B}$ $\left(\mathrm{O}_{3}+2 \mathrm{H}^{+}+2 e \leftrightarrow \mathrm{O}_{2}+\mathrm{H}_{2} \mathrm{O}\right)$ [10], is inferior in size only to fluorine $(2.87 \mathrm{~B})\left(\mathrm{F}_{2}+2 e \leftrightarrow 2 \mathrm{~F}^{-}\right)$.
With decomposition of 2 moles of ozone, $297.5 \mathrm{~kJ}$ of heat is released. The observed activity of ozone is due both to its direct (molecular) effect and to the emergence, in the course of decomposition, of the socalled singlet oxygen ${ }^{1} \mathrm{O}_{2}$ in an electronically excited state, and other radicals. In [11], the authors prove the possibility of its emergence in the most reactive form, i.e. protonated ozone $\mathrm{HO}_{3}^{+}$. The solubility of ozone in water is more than 15 times higher than that of oxygen and depends on the hydrogen index and the amount of impurities in water [12-14].

One way to influence gas formation in a liquid is an ultrasonic effect in a range of particular frequencies $[15,16]$. When an ultrasonic wave propagates in a liquid phase, a multitude of microscopic bubbles burst with the release of a large amount of energy at the $\mathrm{L} / \mathrm{S}$ interface and the occurrence of high pressures and temperatures. Gas inclusions in a liquid play the role of cavitation nuclei.

\section{Experiment}

Samples of $20 \times 20 \times 3$ size, made of D16 or AD31 alloys, were used as an anode. A cathode was stainless steel $12 \mathrm{H} 18 \mathrm{~N} 10 \mathrm{~T}$. The ratio of the area of the anode to the area of the cathode was 1:2.

The PMT- 3 device was used to determine the microhardness of oxide coatings. Wear-resistance tests were carried out using a friction machine of the II 5018 model. A method of immersion in hot oil was used to determine the porosity. The conductive medium was $1-10 \%$ aqueous solution of sulfuric acid. Anodizing was carried out in a galvanostatic mode.

The structure was examined with a JEOLJ5M-6150 scanning electron microscope with a moduleattachment for X-ray spectral analysis and an Integra Aura atomic-power probe microscope (NT-MDT, Russia) using a semi-contact method with sample scanning. To study the chemical composition of the sample surface layers, X-ray photoelectron spectroscopy (XPS) was employed on an SPECS electron spectrometer using $\mathrm{AlK}_{\alpha}$-radiation $(1486.6 \mathrm{eV})$ in a combination with layer-by-layer etching of the surface with $4-\mathrm{keV}$ argon ions. To determine the elemental composition of the coatings, an X-ray spectral microanalyzer was used (an EDAX attachment to a Philips SEM-515 microscope).

Phase composition was studied by X-ray diffraction on a D8 Advance diffractometer (Bruker AXS) in $\mathrm{CuK}_{\alpha^{-}}$ radiation. To identify the phases by X-ray diffraction data, a PDF-2 phase bank (ISCD) was used.

Anodizing in a sulfate electrolyte saturated with active oxygen. A schematic diagram of anodizing process with ozone-air mixture passing is presented 


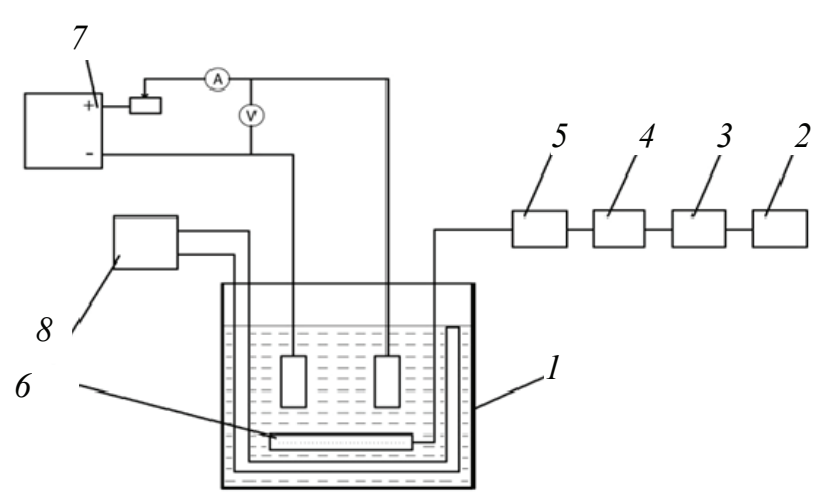

Fig. 1. Schematic diagram of anodizing process with ozone-air mixture passing through the electrolyte: 1 - bath; 2 - compressor; 3 - absorption air dehumidifier; 4 - rotameter; 5 - ozone generator; 6 - bubbler;

7 - direct current source; 8 - refrigeration unit

in Fig. 1. The air was pumped into the delivery system by compressor 2 of SO-45A type, passed through absorption dehumidifier 3 (HLS-R012-HL0030), then to ozonator 4 (OZONE-5PV1) with a capacity of $16 \mathrm{~g} / \mathrm{m}^{3}$. The ozone-air mixture was supplied to bath 1 , filled with electrolyte. The content of ozone in the air was determined by Medozon 254/5, in the liquid by Medozon 254/5L. The flow rate of the gas-air mixture was adjusted by rotameter 5 . The BCA-5K selenium rectifier was used as a direct current source, which made it possible to regulate the current intensity in the range from 0 to $20 \mathrm{~A}$.

\section{Results and Discussion}

X-ray photoelectron spectroscopy was used to determine the chemical composition of the oxide layer formed on the D16 alloy in the ozonized sulfuric acid electrolyte. Figure 2 shows a series of photoelectron spectra of O1s (532 eV), C1s (286 eV), Al2p (75 eV), Al2s $(120 \mathrm{eV})$, Auger spectrum of aluminum $(\sim 102 \mathrm{eV})$.

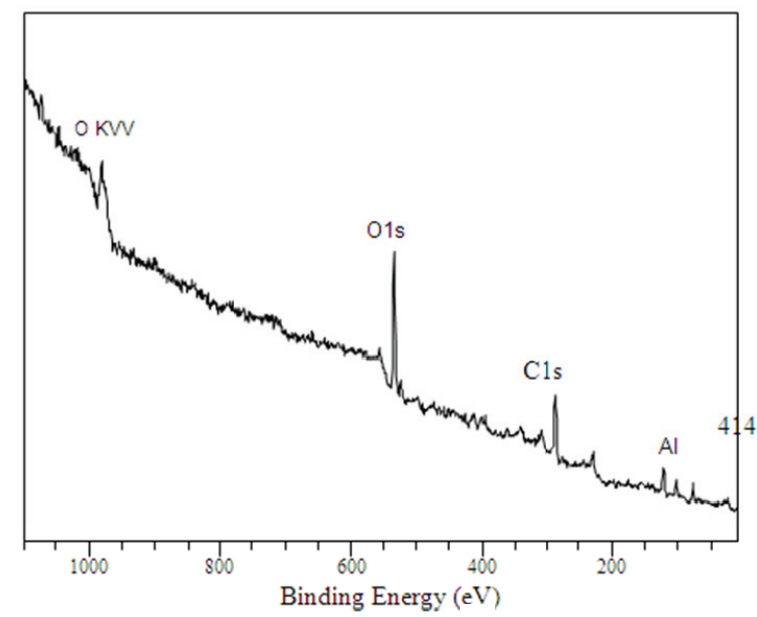

Fig. 2. The spectrum of the surface layer at a depth of $5 \mathrm{~nm}$, formed in a $10 \%$ solution of $\mathrm{H}_{2} \mathrm{SO}_{4}$ at a temperature of $10{ }^{\circ} \mathrm{C}$, a current density of $10 \mathrm{~A} / \mathrm{dm}^{2}$ and an ozone concentration in the air mixture of $3 \mathrm{mg} / \mathrm{l}$
In small quantities, silicon is found, and sulfur in the trace. The concentrations of elements in the surface layer (atomic percentages) are given in Table 1. The concentrations are calculated by the integrated intensities of the corresponding spectra, taking into account the coefficients of element sensitivity and SpecsLab database.

From Table 1 it follows that, with the exception of the outer layer containing adsorbed oxygen, at a depth of 0.5 to $5 \mathrm{~nm}$, the ratio of the oxygen concentration to the aluminum concentration is close to 1.5 , which corresponds to the stoichiometry of $\mathrm{Al}_{2} \mathrm{O}_{3}$. The main, most intense oxygen peak confirms its bond with aluminum $\left(\mathrm{Al}^{3+}\right)$. It corresponds to a binding energy of $531.9 \mathrm{eV}$, which is characteristic of $\mathrm{Al}_{2} \mathrm{O}_{3}$.

Figure 3 shows the experimental spectra of aluminum A12p and Auger-spectra at a depth of 0.5 and $5 \mathrm{~nm}$. From the figure it follows that aluminum spectra are single-component. Both observed peaks refer to oxidized aluminum $\left(\mathrm{Al}^{3+}\right)$ since there are no lines of metallic aluminum on the spectrum of the Auger-region, and the Auger-peak of the oxide is single.

Hence, there is an inhomogeneous surface charge due to the differentiation of the composition of the surface layer. In this case, $E_{\text {bond }}$ (A12p) is $74.9 \mathrm{eV}$, which also corresponds to the oxidation of aluminum up to $\mathrm{Al}^{3+}$ and $\mathrm{Al}_{2} \mathrm{O}_{3}$ formation. The plasmon peak in the spectrum of the reference aluminum sample lies at a distance of $\sim 15.3 \mathrm{eV}$ from the main peak of metallic aluminum $(2 \mathrm{p}, 72.9 \mathrm{eV})$ and is related to the energy loss of photoelectrons to excite plasmons in the surface layer of metallic aluminum of the reference sample.

The position of Auger-peaks of KLL aluminum on the binding energy scale in the ozone-treated D16 alloy also corresponds to the formation of $\mathrm{Al}$ (III) aluminum oxides $(100 \mathrm{eV})$. To identify the chemical state of aluminum, the Auger parameter $\left(\alpha=E_{\text {kin }}\right.$ (Auger) $\left.+E_{\text {bond }}(\mathrm{A} 12 \mathrm{p})\right)$ was additionally used.

Table 1

The content of elements in the surface layer of D16 alloy and the reference aluminum sample, at. \%

\begin{tabular}{lcccccc}
\hline Sample & $\begin{array}{c}\text { Depth, } \\
\mathrm{nm}\end{array}$ & $\mathrm{O}$ & $\mathrm{Al}$ & $\mathrm{Si}$ & $\mathrm{S}$ & $\mathrm{C}(\mathrm{O}) / \mathrm{C}(\mathrm{met})$ \\
\hline \multirow{4}{*}{414} & 0 & 36.5 & 9.6 & 2.5 & & 3.02 \\
& 0.5 & 32.7 & 16.0 & 2.6 & $\mathrm{tr}$ & 1.76 \\
Reference & 0 & 33.1 & 19.9 & & & 1.42 \\
sample & 0.5 & 45.3 & 47.7 & 0 & 0 & 0.95 \\
Al & 6.5 & 7.9 & 87.6 & & & 0.09 \\
\hline
\end{tabular}




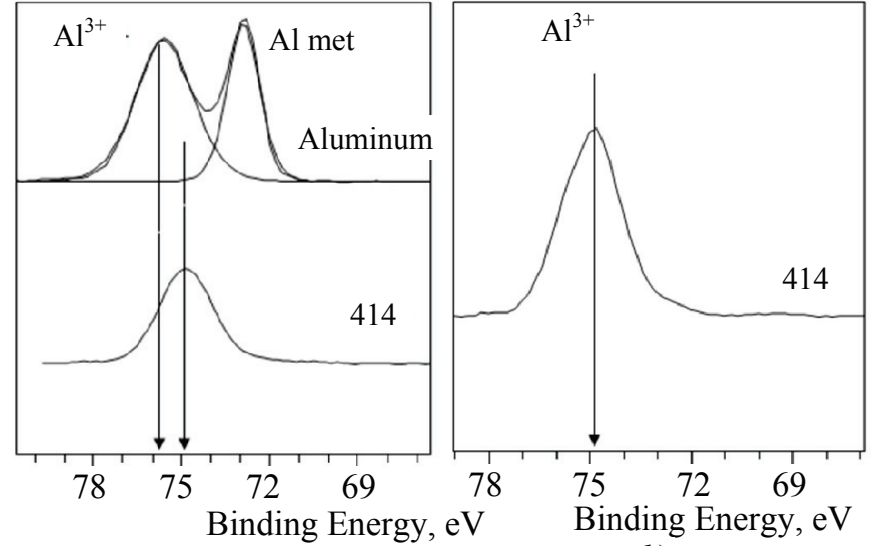

a)

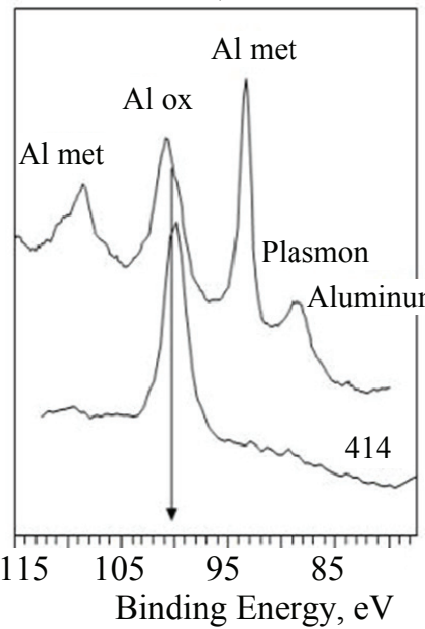

c) b)

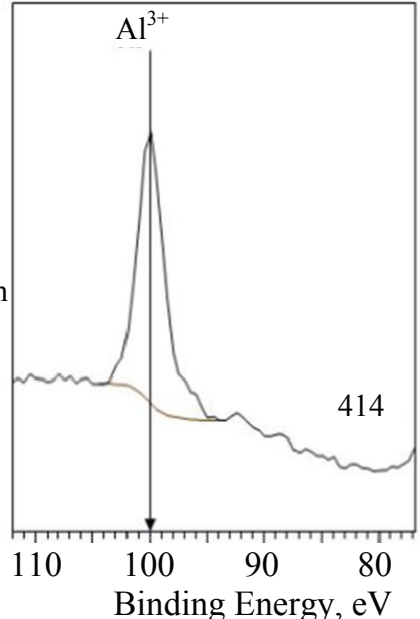

d)

Fig. 3. Spectra of aluminum:

$a-\mathrm{Al} 2 \mathrm{p}$, depth $0.5 \mathrm{~nm} ; b-\mathrm{Al} 2 \mathrm{p}$, depth $5 \mathrm{~nm}$;

$c$-Auger, depth $0.5 \mathrm{~nm} ; d$-Auger, depth $5 \mathrm{~nm}$

The obtained value of the Auger-parameter is $\sim 1461.5 \mathrm{eV}$ and corresponds to the oxidation of aluminum up to a charge of $3+$ with the formation of $\mathrm{Al}_{2} \mathrm{O}_{3}$. The above data, on the whole, confirm the formation of $\mathrm{Al}_{2} \mathrm{O}_{3}$ in the surface layers after the sample is treated in the ozonized solution.

In addition to aluminum and oxygen, weakly intense silicon peaks of Si2s and sulfur S2p were found on the sample spectra, Fig. 4. The position of silicon lines ( $E_{\text {bond }} \sim 155 \mathrm{eV}$ ) corresponds to its maximum oxidation degree to $4+$.

The binding energy of sulfur atoms $(176 \mathrm{eV})$ has the maximum possible value. Similar values of the binding energy are characteristic for compounds in which sulfur is part of the acid residue $\left(\mathrm{SO}_{4}^{2-}\right)$. Moreover, the chemical shift significantly exceeds the shift value for $\mathrm{SO}_{3}(168-169 \mathrm{eV})$ and sulphides over the Me-S bond $(152-163 \mathrm{eV})$.

$\mathrm{X}$-ray spectral microanalysis was used to analyze the distribution of elemental composition. According to the profile of elements distribution presented in Fig. 5, copper and magnesium are located in the substrate of D16 alloy. Carbon is found only

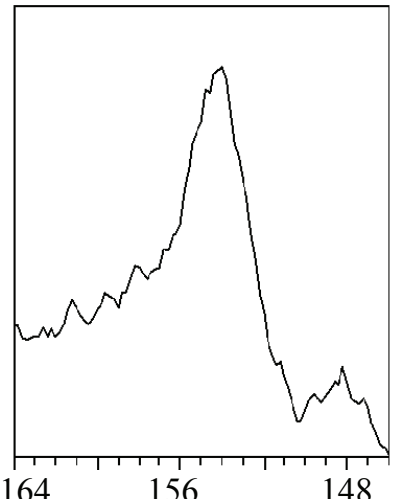

164

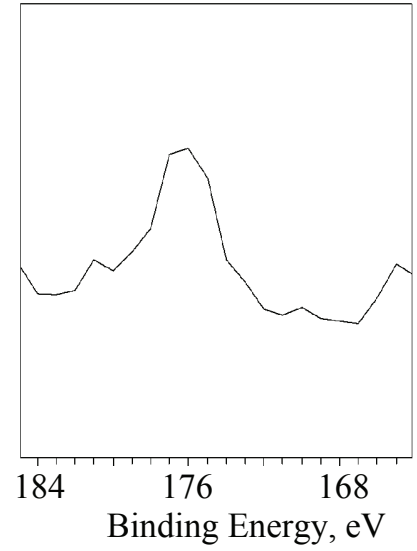

b)

a)

Fig. 4. Spectrum at a depth of $0.5 \mathrm{~nm}$ : $a-\mathrm{Si} 2 \mathrm{~s} ; b-\mathrm{S} 2 \mathrm{p}$

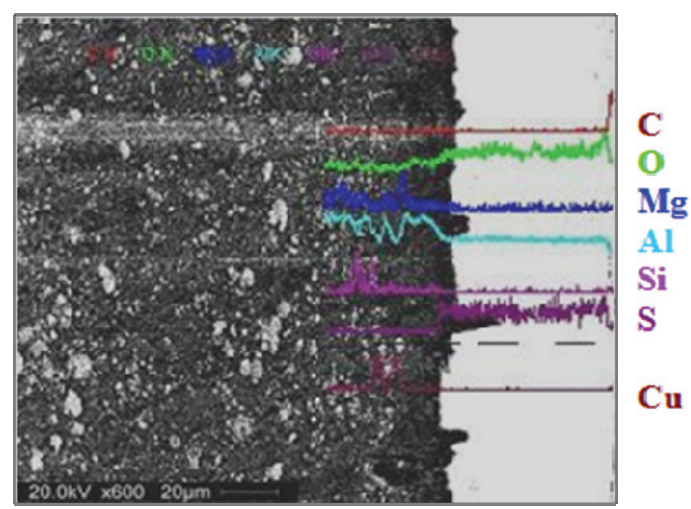

Fig. 5. The profile of elements distribution along the scanning line obtained on D16 alloy

in the surface layer. Most of the silicon is located in the substrate, a small part of it is found in the coating. Sulfur is mainly contained in the coating. As for oxygen distribution, its maximum is observed in the surface layer with a small subsequent decrease, and later on its concentration does not change until the end of coating. The increased presence of oxygen $(7.18 \%)$ under the barrier layer (Fig. 6) confirms its saturation in the pore space. According to [17], the concentration of oxygen in aluminum alloys is $(2.5-5) \cdot 10^{-3} \%$.
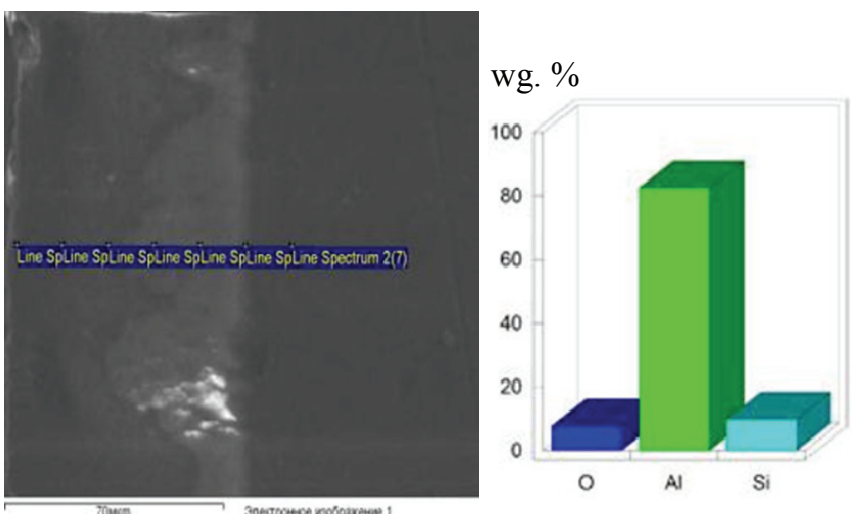

Fig. 6. The results of spectral analysis of the end part of D16 alloy 
Table 2

Mass fraction of oxygen and aluminum

\begin{tabular}{cccc}
\hline LineSpectrum & $\mathrm{B}$ (stat.) & $\mathrm{O}$ & $\mathrm{Al}$ \\
\hline $2(1)$ & & 45.08 & 46.10 \\
$2(2)$ & & 40.83 & 42.75 \\
$2(3)$ & & 42.04 & 42.67 \\
$2(4)$ & Yes & 44.36 & 45.24 \\
$2(5)$ & & 40.84 & 42.01 \\
$2(6)$ & & 40.39 & 45.21 \\
$2(7)$ & & $\mathbf{7 . 1 8}$ & $\mathbf{7 2 . 9 3}$ \\
\hline
\end{tabular}

The mass fraction of oxygen and aluminum, according to the spectra, is given in Table 2. Using the $\mathrm{X}$-ray diffraction method, we studied the phase composition of oxide films formed on AD31 alloy and obtained using different processing modes. In all the samples an amorphous phase was found, which was observed in the angular interval $2 \theta=(20-40)^{\circ}$.

Figure 7 shows the X-ray diffraction patterns of the oxide layer obtained on AD31 alloy in a $10 \%$ sulfuric acid electrolyte solution at a temperature of $10{ }^{\circ} \mathrm{C}$ and a current density of $5 \mathrm{~A} / \mathrm{dm}^{2}$. On the $\mathrm{X}$-ray patterns, characteristic peaks are observed, which testifies to the presence of the crystalline phase. By angular marks, the interplanar distances and the phase composition of the coating were determined.
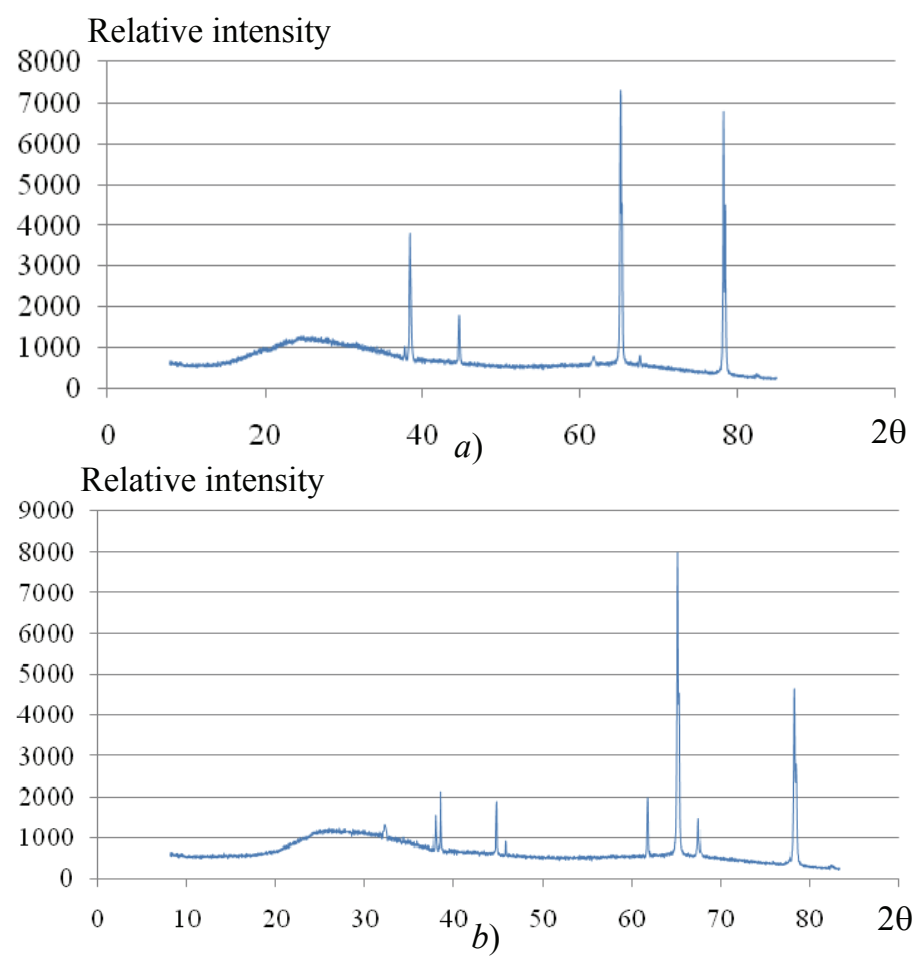

Fig. 7. The X-ray diffraction pattern of the oxide layer formed on the AD31 alloy at ozone concentration, $\mathrm{mg} / \mathrm{l}$ : $a-1 ; b-5$
The most intense peaks in units of $2 \theta$, equal to 38.50 ; $44.78 ; 65.14$, correspond to the crystalline base aluminum. Less intense peaks at angles 20: 37.77 , $45.95,60.95$ are identified as a modification of $\gamma-\mathrm{Al}_{2} \mathrm{O}_{3}$ aluminum oxide.

With increasing ozone concentration in the air mixture, the intensity of the lines increases, which confirms the presence of the crystallization process of the coating. A change in the thermal condition in the pore volume contributes to the occurrence of crystalline oxides. Decomposition of free ozone in the pore space occurs with the release of heat $(\sim 144 \mathrm{~kJ} / \mathrm{mol})$, and the heat of the chemical reaction of oxide formation [3] is $501.2 \mathrm{~kJ} / \mathrm{mol}$. This creates the conditions for crystal formation. A change in the temperature conditions in the electrolytic solution is indicated by the frequency of sensor triggering, which controls the constancy of the temperature mode.

The results of morphological studies of the surface layer on a probe microscope are presented in $3 \mathrm{D}$ format in Fig. 8. The surfaces are formed in a $10 \% \mathrm{H}_{2} \mathrm{SO}_{4}$ solution. The protruding formations on the surface of the film should be considered as crystalline forms.

This assumption correlates with the results of studies of the phase composition of the oxide layer, shown in Fig. 9. Darker areas are phase structures with
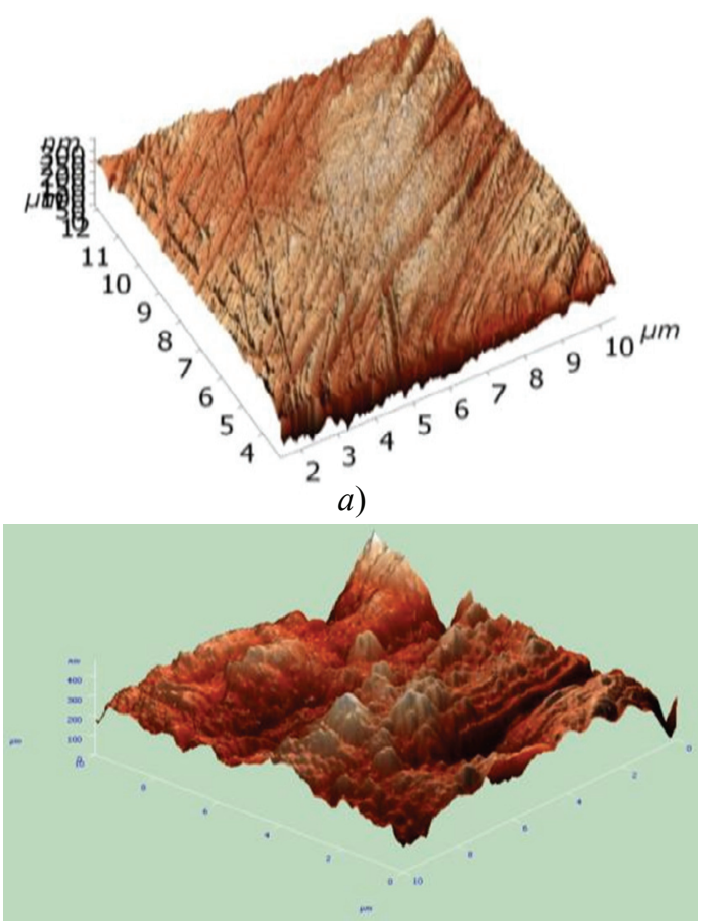

b)

Fig. 8. The microgeometry of the D16 alloy surface formed at an electrolyte temperature of $10{ }^{\circ} \mathrm{C}$ : $a$-in a medium without ozone and a current density of $10 \mathrm{~A} / \mathrm{dm}^{2} ; b-$ in an ozonized medium $(3 \mathrm{mg} / \mathrm{l})$ and a current density of $5 \mathrm{~A} / \mathrm{dm}^{2}$ 


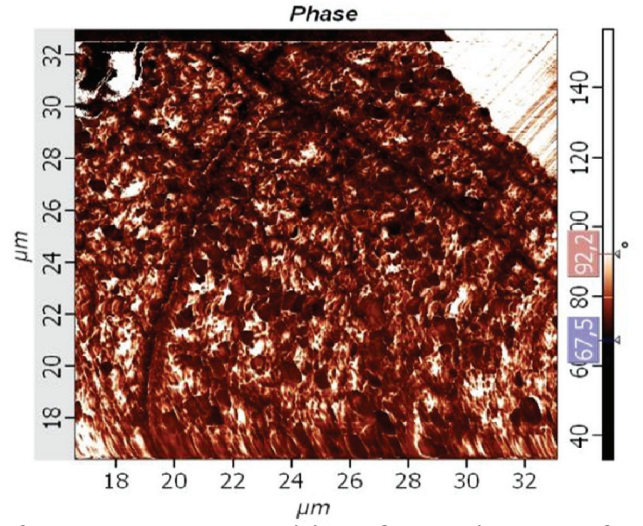

Fig. 9. The phase composition of the oxide layer formed on the D16 alloy in the ozonized electrolyte

denser packing of atoms, which can be regarded as crystalline phases $\gamma-\mathrm{Al}_{2} \mathrm{O}_{3}$. For example, the phase composition of the surface (Fig. 10), formed by classical anodizing on a casting alloy, practically does not have any dark areas.

An increase in the ozone concentration from 1 to $5 \mathrm{mg} / \mathrm{l}$ leads to an increase in porosity by $26 \%$, which is explained by the presence of increased gas formation and a change in temperature conditions during the decay of ozone in the pore volume.

The study of the cross sections of oxide films, formed in the ozonized solution, showed that along with the pores typical of conventional anodization, pores which significantly exceed the first ones by their dimensions are formed. We take them for megapores, or filamentary channels, whose effective diameter is $1-3 \mu \mathrm{m}$.

Figure 11 shows the structure of the pores formed on D16 alloy. The process of oxidation begins with the formation of microbreaks and the nucleation of the hole, which is the beginning of the emerging pore. In general, the anode process involving ozone does not change the classical pattern of pore nucleation. However, the corrections are made by thermal energy during the decomposition of ozone at the boundary with a metal, significantly increasing the etching rate in individual places.

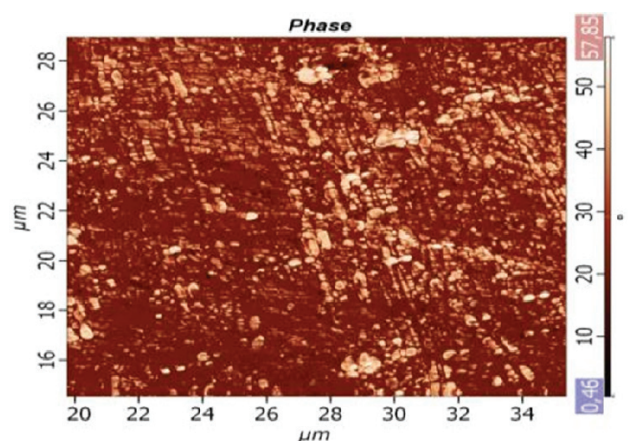

Fig. 10. The phase composition of the surface formed on the AL2 alloy by classical anodizing without ozone at an electrolyte temperature of $10{ }^{\circ} \mathrm{C}$ and a current density of $10 \mathrm{~A} / \mathbf{d m}^{2}$

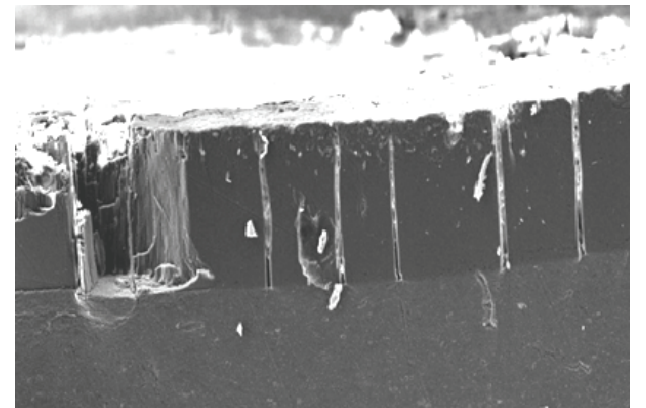

Fig. 11. An oxide film on D16 alloy at 95-fold magnification with the formation of large threadlike channels formed in a $5 \% \mathrm{H}_{2} \mathrm{SO}_{4}$ solution at an ozone concentration of $5 \mathrm{mg} / \mathrm{l}$, a current density of $5 \mathrm{~A} / \mathrm{dm}^{2}$ and an electrolyte temperature of $10^{\circ} \mathrm{C}$

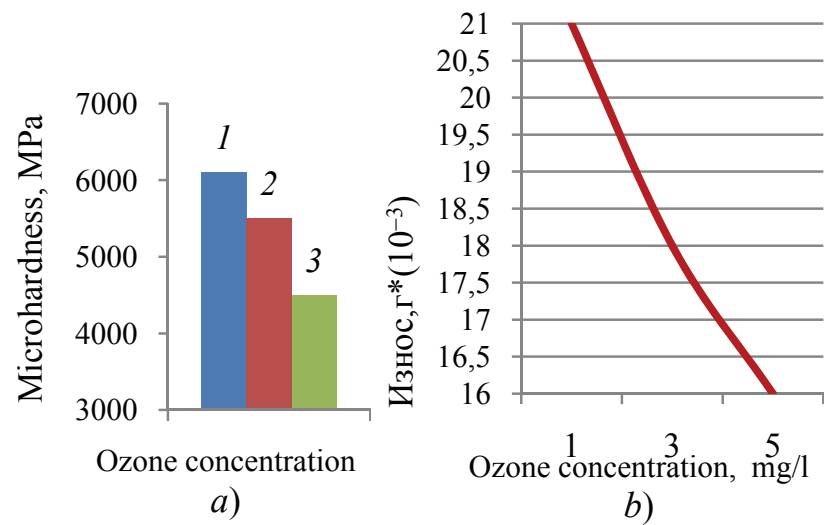

Fig. 12. Microhardness $(a)$ and wear resistance $(b)$ of the oxide coating as a function of the ozone concentration passed through a $10 \% \mathrm{H}_{2} \mathrm{SO}_{4}$ solution at a current density of $5 \mathrm{~A} / \mathrm{dm}^{2}$ and a medium temperature of $10^{\circ} \mathrm{C}$

With an increase in ozone concentration involved in the process, the rate of oxidation increases. The coating is formed, basically, during the first $40 \mathrm{~min}$. Probably, the intensification of coating growth is associated with the redistribution of ion density in the near-electrode region. The introduction of ozone explicitly indicates the presence of reaction of interaction between aluminum and atomic oxygen in the region.

As the ozone concentration increases, the microhardness and wear resistance of the coating increase (Fig. 12), which is due to an increase in the crystalline phase in the oxide structure.

Anodizing in ozonized sulfate electrolyte in a cavitation mode. The scheme of the experimental setup is shown in Fig. 13. Anodizing was carried out with an unchanged concentration of ozone in the air mixture, equal to $3 \mathrm{mg} / \mathrm{l}$, with an ultrasonic field applied in the frequency range $20-48 \mathrm{kHz}$ (Fig. 13).

Microscopic studies of the oxide layer showed that there are shells or caverns on its surface formed in an ultrasonic field (Fig. 14). During oxidization in the ozonized solution (Fig. 14, b), the number of cavernous formations (pores) emerging on the 


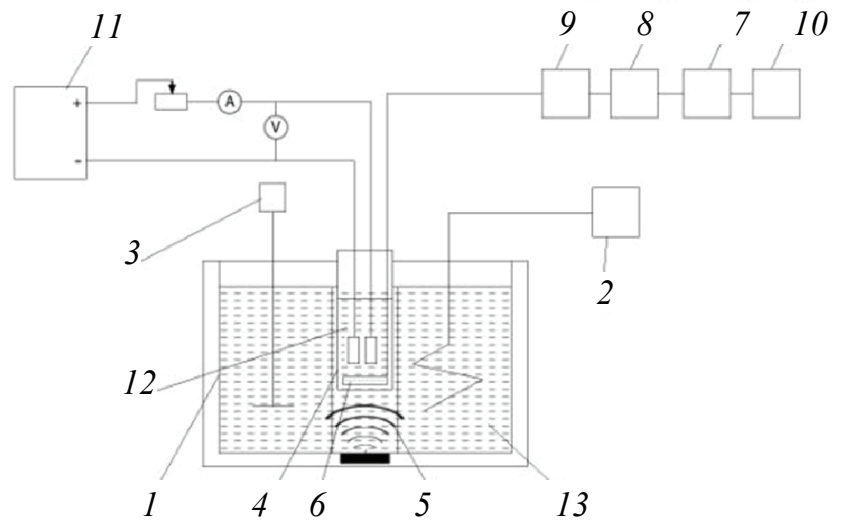

Fig. 13. Anodizing scheme used in the work:

1 - bath with ultrasonic radiator; 2 - cooling unit; 3 - electric mixer; 4 -a glass; 5 - stand for the glass; 6 -bubbler; 7 - air dehumidifier; 8 - ozone generator; 9 - rotameter; 10 - compressor; 11 - power supply; 12 - electrolyte; 13 - liquid for cooling

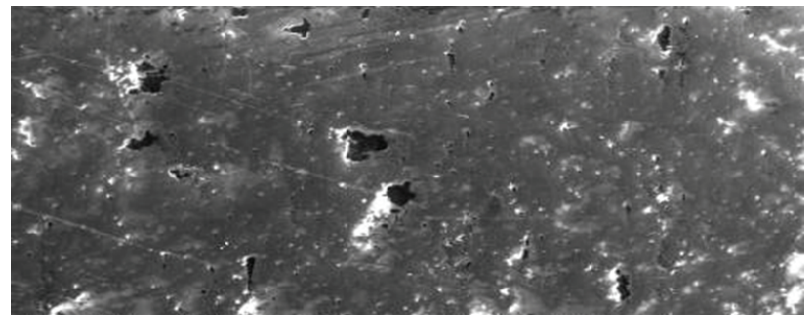

a)

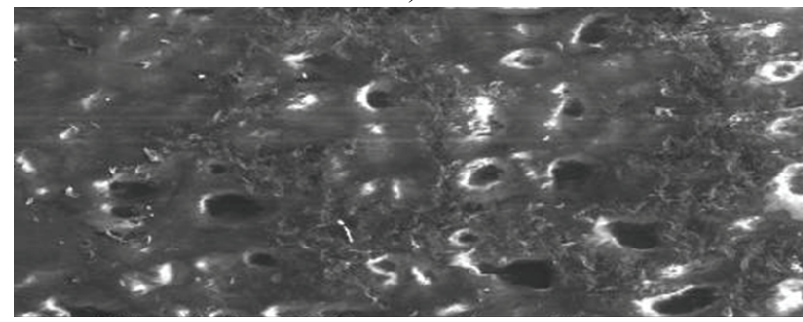

b)

Fig. 14. The state of the oxide surface layer formed on D16 alloy in the galvanostatic mode at a current density of $10 \mathrm{~A} / \mathrm{dm}^{2}$ in a $1 \% \mathrm{H}_{2} \mathrm{SO}_{4}$ solution:

$a$ - in an ultrasonic medium in the absence of ozone;

$b-$ in an ultrasonic medium in the presence of $\mathrm{O}_{3}$

surface is 4-5 times greater in comparison with oxidation without $\mathrm{O}_{3}$ (Fig. 14,a). The microanalysis of the end part of the samples with an oxide layer formed, when applying ultrasound, made it possible to reveal the features of pore formation.

Figure 15 shows the structure of pores formed in sulfuric acid electrolytes using different oxidation methods. With classical anodizing (Fig. 15,a), the cellular structure is clearly observed. Oxidation with ozone-air mixture passed through the electrolyte (Fig. 15,b) is accompanied by the formation of threadlike channels with a size of $1-3 \mu \mathrm{m}$ [18]. When ultrasound is applied, a cavity is formed as a result of cavitation explosions. The filamentary channels serve as a motive for a cavitation event to occur,

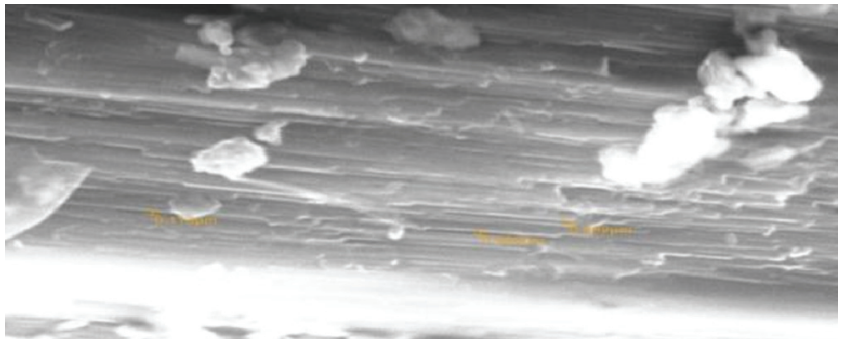

a)

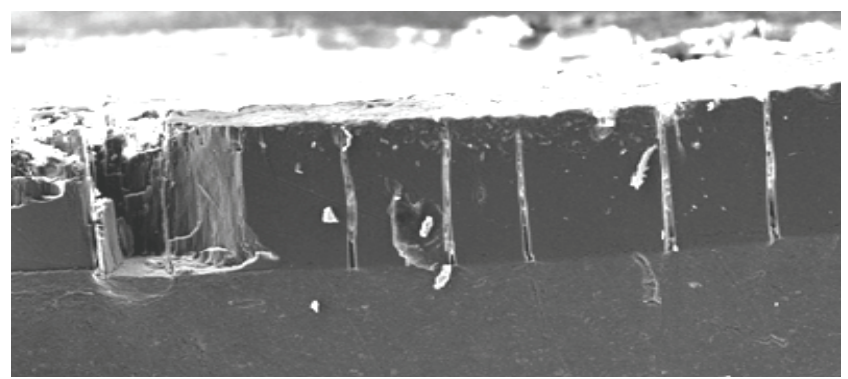

b)

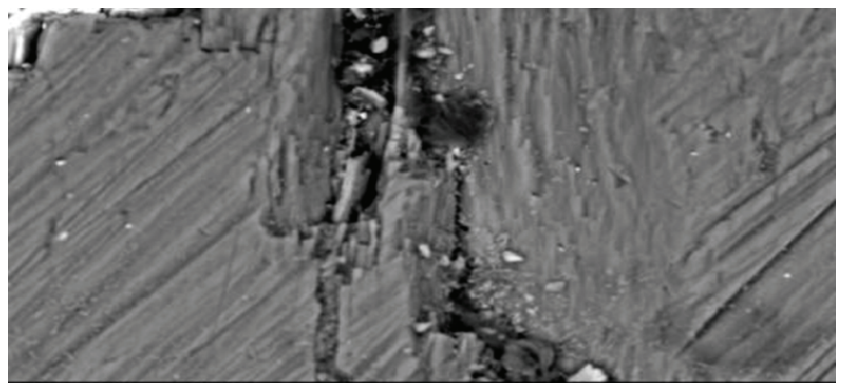

c)

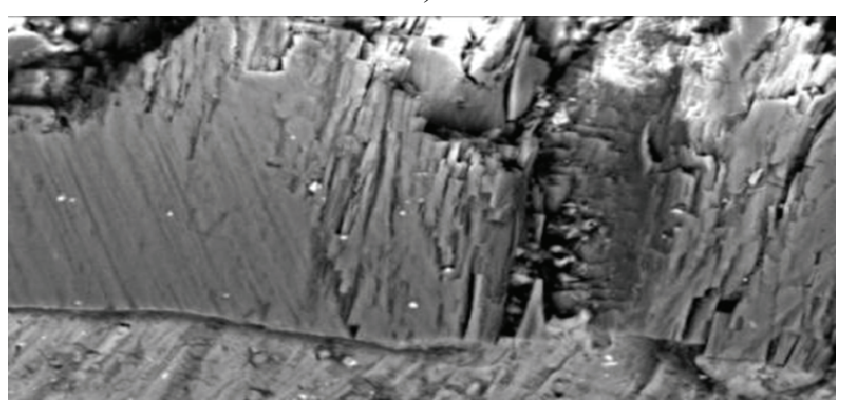

d)

Fig. 15. The nature of the channels in the oxide layer formed in sulfuric acid electrolytes on D16 alloy:

$a$-classical anodizing; $b$ - anodizing in an ozone-containing medium; $c, d$ - anodizing in an ozone-containing electrolyte with an ultrasonic field

as evidenced by the nature of the oxide shown in Fig. 15, $c, d$. In Figure 15, $c$, the upper part of the filamentary pore is widened, and its lower part remains unchanged. Figure 15, $d$ shows a cavern formed through the entire thickness of the oxide. In this case, deformation of the near-porous space is observed, as a result of cavitation phenomena.

The oxide layer surface model in 3-D format was obtained by the probe scanning method (Fig. 16). For comparison, Fig. 16, $a$ shows the surface formed in the 


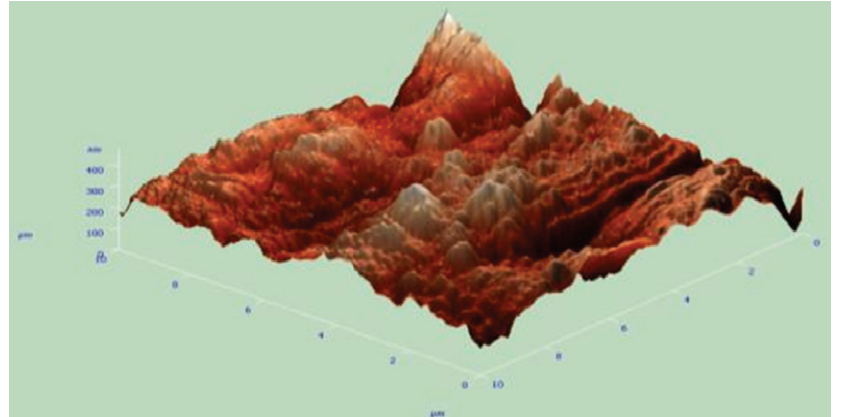

a)

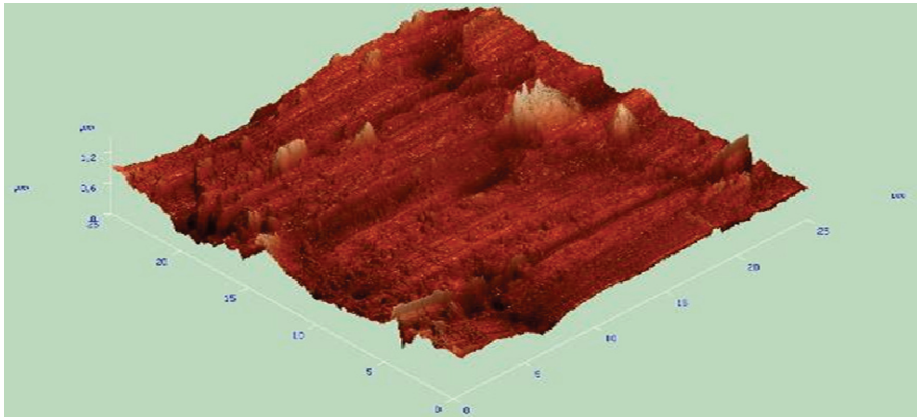

b)

Fig. 16. The oxide surface on D16 alloy formed in a $10 \% \mathrm{H}_{2} \mathrm{SO}_{4}$ solution:

$a$ - with ozone at a current density of $5 \mathrm{~A} / \mathrm{dm}^{2} ; b$ - with ozone in an ultrasonic field at an initial current density of $10 \mathrm{~A} / \mathrm{dm}{ }^{2}$

ozonized electrolyte [19]. Figure 16, $b$ shows the surface formed in the ozonized electrolyte exposed to ultrasound. The conical asperities (Fig. 16), which can be regarded as crystalline oxide formations, are hidden in the pores.

The presence of the crystalline phase of the oxide is also confirmed by the X-ray diffraction analysis data presented in Fig. 17. The most intense peaks observed at angular marks $2 \theta=38.50 ; 44.78 ; 65.14$ and correspond to the crystalline base aluminum. Less intense peaks at angles $20: 37.77^{\circ}, 45.95^{\circ}, 60.95^{\circ}$ - are identified as a modification of $\gamma-\mathrm{Al}_{2} \mathrm{O}_{3}$ oxide.

The results of the phase composition study, presented in Fig. 18, confirm an increase in the concentration of the crystalline phase under ultrasonic action. This is indicated by darker areas in the structure of the coating.
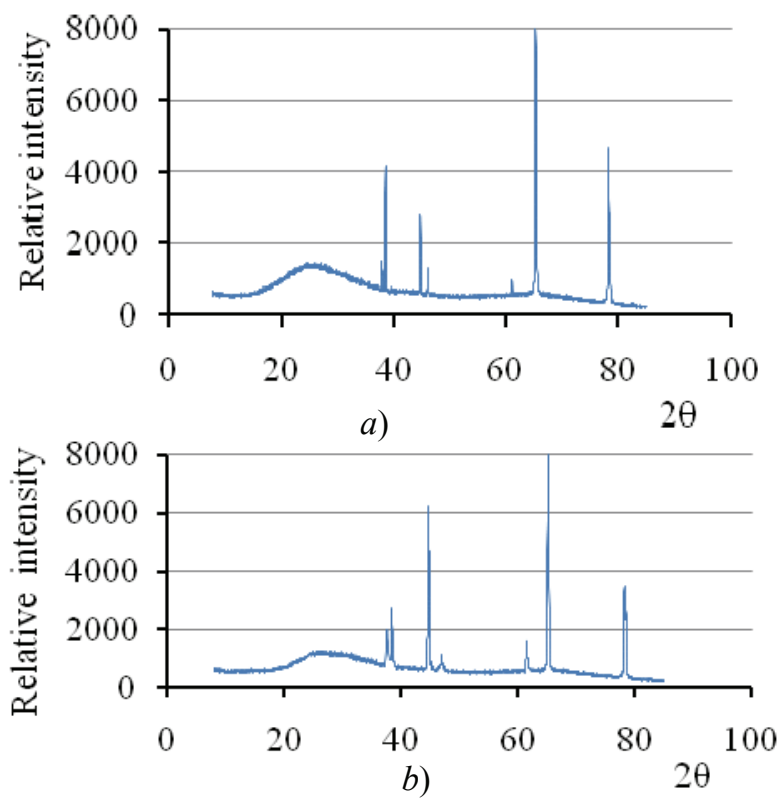

Fig. 17. X-ray diffraction pattern of the oxide layer formed in the incident power mode on the AD31 alloy at an initial voltage of $75 \mathrm{~V}$ and ozone concentration in the air mixture of $3 \mathrm{mg} / \mathrm{l}$ :

$a$ - without an ultrasonic field; $b$ - with an ultrasonic field
An increase in the number of cavernous channels during anodizing in the presence of an ultrasonic field in an ozone-containing medium is most likely due to a greater solubility of ozone than oxygen in the sulfuric acid electrolyte. With increasing gas concentration in the liquid, the probability of formation of embryos, participating in cavitation, and their number increases. At the moment when gas bubbles collapse, gas pressure and temperature reach significant values (according to some data up to $100 \mathrm{MPa}$ and $10,000{ }^{\circ} \mathrm{C}$, respectively) [16].

Figure 19 shows fragments of the relief of the inner walls of channels formed in an ultrasonic field.

At the background of small (classical) pores there are large pores, piercing the partitions between the large channels. The lack of correct shapes testifies to the dissolution of oxide walls when exposed to high temperatures and the presence of a significant pressure

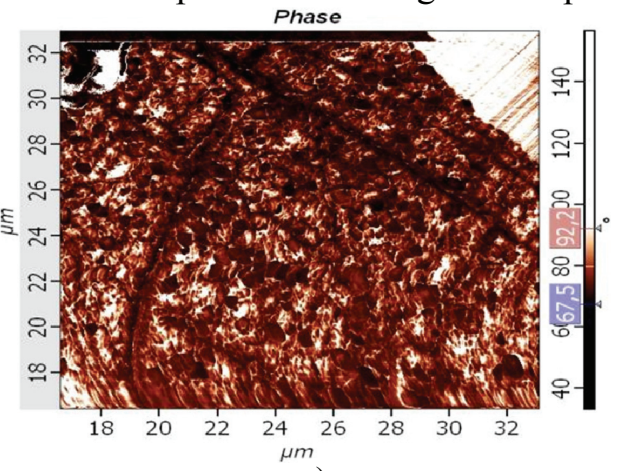

a)

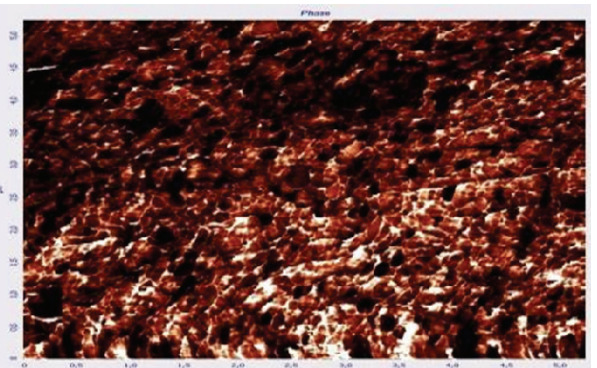

b)

Fig. 18. The density of phase structures in the oxide layer on the D16 alloy formed in the ozonized electrolyte: $a$-without an ultrasonic field; $b$ - with an ultrasonic field 
a)

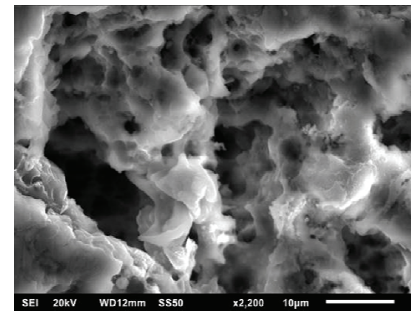

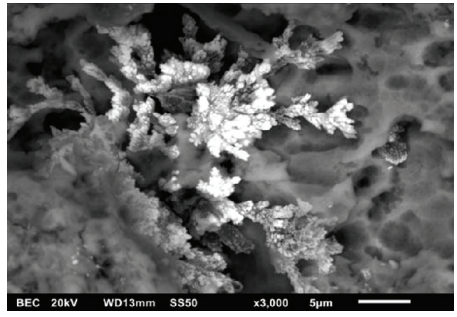

b)
Fig. 19. The morphology of a pore in an oxide layer, formed on the D16 alloy by anodizing in an ultrasonic bath with ozone-air mixing of the electrolyte: $a$ - the relief of the pore walls; $b$ - the pore, overgrown with crystals

at the time bubble collapses. At a greater magnification, crystalline formations of a dendritic form were detected as a result of the processes of interaction between active oxygen and metal ions diffusing from the bottom of the pore.

Cross-sectional studies by means of scanning electron microscopy in the mode of reflected electrons, shown in Fig. 20, confirm the formation of phase structures with a more dense packing of atoms in the megapore or cavern formation zones.

Phase distribution occurs parallel to the pore formation vector. X-ray spectral analysis shows the distribution of chemical elements ( $\mathrm{O}$ and $\mathrm{Al})$ after anodic treatment of an aluminum alloy in an ozonized electrolyte $\left(10 \% \mathrm{H}_{2} \mathrm{SO}_{4}\right)$ exposed to ultrasound. Analysis of the obtained results showed that the amount of oxygen and aluminum in the formed layer is in a ratio of $3: 2$, which confirms the formation of $\mathrm{Al}_{2} \mathrm{O}_{3}$ oxide. An increased oxygen content (up to 22 wt. \%) under the barrier layer was observed.

Figure 21 shows the spectra of oxygen and aluminum at the boundary of the barrier layer. Deeper diffusion of oxygen into the main material is determined by the cumulative nature of the processes during cavitation collapses. The temperature and pressure of gases in the channel volume when a cavitation event occurs are a kind of "gunpowder" charge, and oxygen is like a "flying missile" along the conduction channel in the direction of the main material.

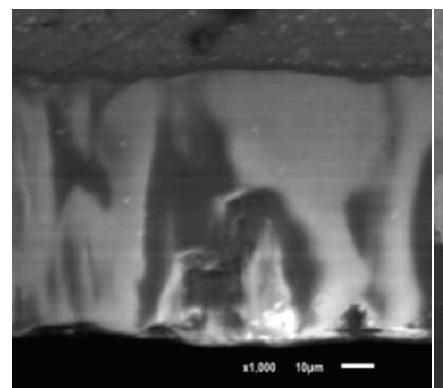

a)

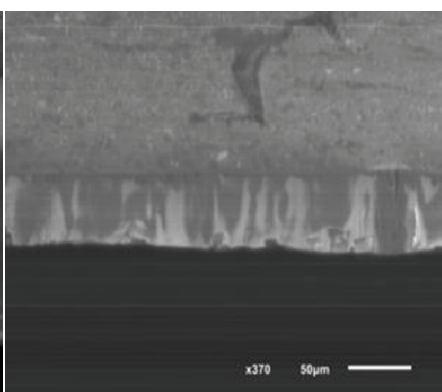

$b$
Fig. 20. Phase distribution in the oxide layer formed on the D16 alloy in an ozonized medium exposed to an ultrasonic field. Magnification factor: $a-1000 ; b-370$

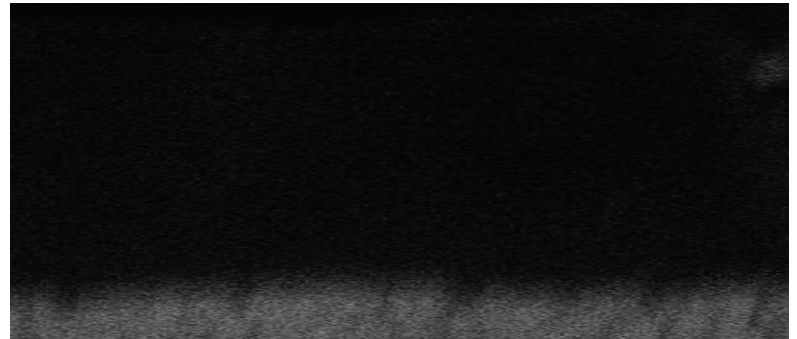

Fig. 21. The map of the distribution of oxygen and aluminum at the metal-oxide interface on D16 alloy

The stretched black bands represent oxide formations, formed as a continuation of filamentary channels. Thus, the presence of oxygen on both sides of the boundary, separating the base metal and the oxide, can be considered the result of an increase in the density of active gas in pore space.

The microhardness of the oxide layer, formed in electrolytes with concentration $(1-10) \% \mathrm{H}_{2} \mathrm{SO}_{4}$, when the current density was varied from 1 to $10 \mathrm{~A} / \mathrm{dm}^{2}$, was in the range of $(8-9) \cdot 10^{3} \mathrm{MPa}$.

A comparative analysis of the wear resistance of oxide coatings, formed by different technologies on the alloy, is shown in Fig. 22.

An increase in wear resistance of the oxide layer is due to the formation of hardness islets, formed from crystalline aluminum oxides. It is worth noting that when the porous space is filled with hot oil, the wear resistance of the coating increases more than threefold (Fig. 23).

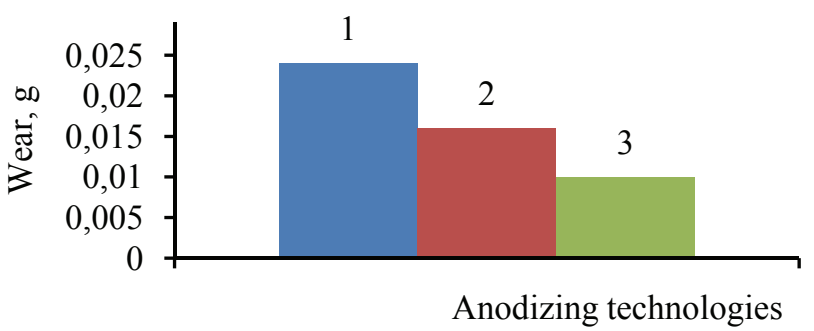

Fig. 22. The wear of the oxide coating, formed using various technologies of anodizing D16 alloy: 1 - classical anodizing; 2 - anodizing in an ozonized electrolyte; 3 - anodizing in an ozonized electrolyte under ultrasound exposure

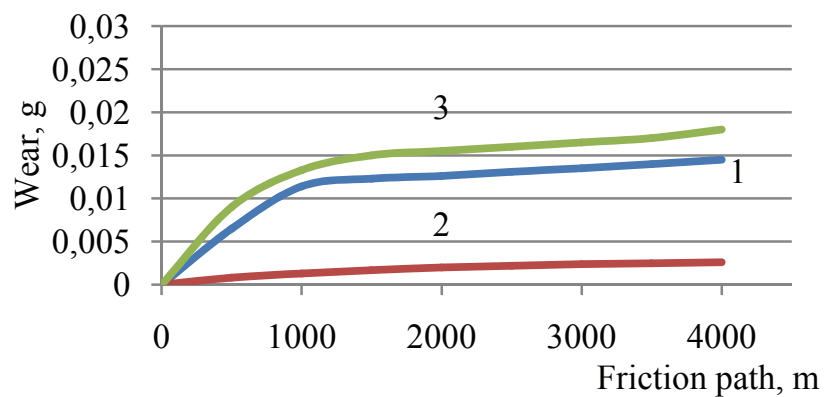

Fig. 23. The wear of oil-impregnated oxide coatings, formed on D16 alloy:

1 - ozonized electrolyte; 2 - ozonized electrolyte exposed to ultrasonic field; 3 - classical anodization 


\section{Conclusion}

When aluminum alloys are anodized in the ozonecontaining sulfate electrolyte, in the surface layer, along with an amorphous structure, crystalline modification $\gamma-\mathrm{Al}_{2} \mathrm{O}_{3}$ is formed. The presence of excess oxygen under the barrier layer confirms an increase in the density of active oxygen in the pore space.

The presence of ozone in the electrolyte during anodizing is accompanied by the occurrence of filamentary channels with a diameter of $1-3 \mu \mathrm{m}$, which increases the total porosity by $26 \%$ and intensifies the process of oxide formation by $30 \%$.

As a result of anodizing with ozone, surface properties are improved in comparison with classical anodizing: the microhardness increases by $27 \%$ and wear resistance by $60 \%$. Anodizing in the ozonized electrolyte exposed to the ultrasonic field is accompanied by an increase in the crystalline phase $\gamma-\mathrm{Al}_{2} \mathrm{O}_{3}$ in the oxide layer up to $18-27 \%$.

The wear resistance of oxide coatings on D16 alloy in the ozonized sulfuric acid electrolyte exposed to ultrasonic field increases 2.2 times in comparison with the classical version of anodizing, which is due to the formation of a solid crystalline phase and the morphology of the formed surface. The wear of the hardened surface, formed in the ozonized medium under ultrasonic field exposure and impregnated with oil, reduces 3.3 times in comparison with the dry surface. The microhardness of the oxide layer, caused by the occurrence of the crystalline phase $\left(\gamma-\mathrm{Al}_{2} \mathrm{O}_{3}\right)$ where crater-like channels are formed, increases to $8910 \mathrm{MPa}$.

The work was partially funded by the grant from the President of the Russian Federation for leading scientific schools (NSh 9730.2016.11).

\section{References}

1. Kirsanov N.M. Primenenie alyuminievyih splavov $v$ stroitelstve [Application of aluminum alloys in construction]. Voronezh: Izd-vo VSU, 1960. 56 p. (Rus)

2. Messi G. Otritsatelnyie ionyi [Negative ions]. M.: Mir, 1979. 754 p. (Tr. from Eng)

3. Tomashov N.D., Tyukina M.N., Zalivalov F.P. Tolstosloynoe anodirovanie alyuminiya $i$ ego splavov [Thick-layer anodizing of aluminum and its alloys]. M.: Machine Building, 1968. 155 p. (Rus)

4. Mak-Taggart F. Plazmohimicheskie reaktsii $v$ elektricheskih razryadah [Plasma-chemical reactions in electrical discharges]. M.: Atomizdat, 1972. 256 p. (Rus)

5. Golubev A.I. Anodnoe okislenie alyuminievyih splavov [Anodic oxidation of aluminum alloys]. M.: Izd-vo AS USSR, 1961. 201 p. (Rus)
6. Yakovleva N.M. Strukturno-morfologicheskie zakonomernosti formirovaniya nanoporistyih oksidov alyuminiya: dis. ... d-ra fiz.-mat. nauk [Structuralmorphological regularities in the formation of nanoporous aluminum oxides]. Petrozavodsk, 2003. 362 p. (Rus)

7. Sokol V.A. Osobennosti rosta poristogo oksida alyuminiya [Peculiarities of porous aluminum oxide growth]. Reports of BGUIR, 2003, vol.1, no.1, pp. 75-82. (Rus)

8. Yung L. Anodnyie oksidnyie plenki [Anodic oxide films]. Leningrad: Energy, 1967. 231p. (Rus)

9. Patermarakis G., Tzouvelekis D. Development of a strict kinetic model for the growth of porous anodic A1203 films on aluminium. Electrochim. Acta, 1994, vol. 39, no. 16, pp. 2419-2429.

10. Lunin V.V., Popovich M.P., Tkachenko S.N. Fizicheskaya himiya ozona [Physical chemistry of ozone]. M.: MSU, 1998. 480 p. (Rus)

11. Levanov A.V. Rastvorimost i kinetika gibeli ozona $\mathrm{v}$ vodnyih rastvorah sernoy i fosfornoy kislot [Solubility and kinetics of ozone loss in aqueous solutions of sulfuric and phosphoric acids]. Vestnik of $M S U$, series 2, Chemistry, 2002, vol. 43, no. 5, pp. 286-287. (Rus)

12. Tarasov V.V., Vyiong Thi Lan. Osobennosti kinetiki raspada ozona $\mathrm{v}$ vode [Features of kinetics of ozone decomposition in water]. Water: Chemistry and Ecology, 2009, no. 9, pp. 7-13. (Rus)

13. Razumovskiy S.D., et al. Ozon v protsessah vosstanovleniya kachestva vodyi [Ozone in the processes of water quality restoration]. Journal of All-Russian Chemical Society named after D.I. Mendeleyev, 1990, vol. 35, no. 1, pp. 77-88. (Rus)

14. Orlov V.A. Ozonirovanie vodyi [Ozonation of water]. M.: Stroyizdat, 1984. 375 p.

15. Hmelev V.N., Slivin A.N., Barsukov R.V., et al. Primenenie ultrazvuka vyisokoy intensivnosti $v$ promyishlennosti [Application of high intensity ultrasound in industry]. Biysk: AltSTU, 2010. 203 p. (Rus)

16. Promtov M.A. Perspektivyi primeneniya kavitatsionnyih tehnologiy dlya intensifikatsii himikotehnologicheskih protsessov [Prospects of application of cavitation technologies for intensification of chemicaltechnological processes]. Tambov: Vestnik TSTU, 2008, vol. 14, no. 4. pp. 861-869. (Rus)

17. Egorov S.G., Chervonyiy I.F., Volyar R.N. Prakticheskaya realizatsiya metodov vneshnego vozdeystviya na metallicheskie rasplavyi: monografiya [Practical implementation of methods of external action on metallic melts: monograph]. Zaporozhe: ZGIA, 2012. 222 p. (Rus)

18. Kuskov V.N., Kolenchin N.F., Shadrina P.N., et al. Stroenie i svoystva anodnoy oksidnoy plenki na alyuminii i splave D16 [Structure and properties of anodic oxide film on aluminum and D16 alloy]. Fundamental studies, 2012, no. 11-3, pp. 625-629. (Rus)

19. Kolenchin N.F., Kuskov V.N., Safronov A.V. Stroenie oksidnogo pokryitiya pri anodirovanii alyuminiya $i$ ego splavov [The structure of the oxide coating in anodizing aluminum and its alloys]. Izvestiya of Samarsky research center $R A S, 2014$, vol. 16, no. 4-1, pp. 175-178. (Rus) 